\title{
Genetic Study of Propoxur Resistance-A Carbamate Insecticide in the Malaria Mosquito, Anopheles stephensi Liston
}

\author{
D. Sanil ${ }^{1}$ and N. J. Shetty ${ }^{1,2}$ \\ ${ }^{1}$ Centre for Applied Genetics, Bangalore University, J. B. Campus, Bangalore 560 056, India \\ 2 Janardhana Foundation, Nagadevanahalli, Jnanabharathi Post, Bangalore 560 056, India
}

Correspondence should be addressed to N. J. Shetty, shetty_nj@yahoo.co.in

Received 1 October 2010; Accepted 22 December 2010

Academic Editor: Charles Wondji

Copyright ( $) 2010$ D. Sanil and N. J. Shetty. This is an open access article distributed under the Creative Commons Attribution License, which permits unrestricted use, distribution, and reproduction in any medium, provided the original work is properly cited.

\begin{abstract}
Anopheles stephensi Liston (Diptera: Culicidae) is the urban vector of malaria in the Indian subcontinent and several countries of the Middle East. The genetics of propoxur resistance ( $p r)$ in An. stephensi larvae was studied to determine its mode of inheritance. A diagnostic dose of $0.01 \mathrm{mg} / \mathrm{L}$ as recommended by WHO was used to establish homozygous resistant and susceptible strains. Reciprocal crosses between the resistant and susceptible strains showed an $\mathrm{F}_{1}$ generation of incomplete dominance. The progenies of backcrosses to susceptible parents were in 1:1 ratio of the same phenotypes as the parents and hybrids involved. The dosage mortality $(\mathrm{d}-\mathrm{m})$ lines were constructed for each one of the crosses, and the degree of dominance was calculated. It is concluded that propoxur resistance in An. stephensi larvae is due to monofactorial inheritance with incomplete dominance and is autosomal in nature.
\end{abstract}

\section{Introduction}

The acquisition of insecticide resistance has given one of the best opportunities to assess microevolution processes, partly because the nature of the selective agent is well identified and partly because, in response to this strong selection pressure, evolution is fast [1]. As resistance reflects changes occurring in genotypic architecture of natural populations, a full understanding of the evolution of this phenomenon requires an accurate knowledge of its genetic basis [2]. Resistance to insecticides has appeared in the major insect vectors from every genus [3]. Mosquitoes have developed resistance to all the major groups of insecticides, including biocides [4].

Anopheline mosquito species are obligatory vectors for human malaria, an infectious disease that affects hundreds of millions of people living in tropical and subtropical countries [5]. However, with the emergence of populations of Anopheles capable of withstanding lethal doses of insecticides, the efficacy of insecticide-based vector control tools is critically affected [6]. An. stephensi is one of the important carriers of urban malaria in the Indian subcontinent and roughly accounts for $15 \%$ of the total malaria incidence in India
[7]. The said species has been selected as a model insect for research in our laboratory, since three decades. Considerable data on genetic and cytogenetic studies involving isolation of naturally occurring mutants and establishing Mendelian genetics, isolation of naturally occurring paracentric inversions by using polytene chromosomes, genetic cytological basis of insecticide resistance and the biochemical mechanism involved, isolation and establishment of chromosomal translocations; synthesis of refractory strains for malaria transmission, and so forth, have been generated. Such data shall be used in the synthesis of transgenic strains of the said species. These strains could be used in the genetic control programme of An. stephensi [7-11].

Present investigation was, therefore, undertaken with a view to study the laboratory development of propoxurinduced resistance, inheritance, and degree of dominance of propoxur resistance in An. stephensi.

1.1. Insecticide. Propoxur (Baygon) is a carbamate insecticide (2-isopropoxyphenyl methylcarbamate), with chemical formula $\mathrm{C}_{11} \mathrm{H}_{15} \mathrm{NO}_{3}$. It is approved and registered with the Central Insecticide Board and Registration Committee 
(CIBRC), Ministry of Agriculture, Government of India; World Health Organization (WHO); Environmental Protection Agency (EPA), USA for the use against household pest including mosquitoes. Like other carbamates, propoxur blocks the production and action of cholinesterase, paralyzing the nervous systems of insects causing a rapid "knockdown" effect. Propoxur is found to be effective in the area where mosquitoes were found to be resistant to organophosphate insecticides [12].

\section{Materials and Methods}

2.1. Mosquito Rearing. Thirty strains of An. stephensi derived from different geographical areas of India are currently maintained in our laboratory. Papareddypalya (PRP) strain from Bangalore, India was used to establish the propoxur resistant and susceptible strains, respectively. The adult mosquitoes were maintained at $25 \pm 1{ }^{\circ} \mathrm{C}$ and $75 \pm 5 \%$ relative humidity under 16 hours photoperiods according to the procedure of Shetty [13]. The adults were fed on $10 \%$ sucrose in $8^{\prime \prime} \times 8^{\prime \prime} \times 8^{\prime \prime}$ iron cages covered with cotton net cloth. Females were provided with mice and pigeon as a source for blood meal. Plastic cup ( $3^{\prime \prime}$ diameter) containing clean water lined with filter paper was placed inside the cage for oviposition. The eggs were kept for 72 hours to ensure complete hatching. The hatched larvae were transferred to enamel tray and reared. Powdered mixture of fish feed and dog biscuits were given as larval diet.

2.2. Development of Propoxur-Resistant and PropoxurSusceptible Strains. A WHO diagnostic dosage of $0.01 \mathrm{mg} / \mathrm{L}$ of propoxur was selected and resistance test was carried out according to the procedure of WHO $[14,15]$. The third instar larvae from the isofemale of PRP strain were exposed to $0.01 \mathrm{mg} / \mathrm{L}$ propoxur in two replicates for $24 \mathrm{hrs}$. Larval diet was added to ensure none of the larval mortality occurs due to lack of food. Mortality was recorded after 24 hours. Moribund larvae (presenting weakness and rigidity or mobility of reach water surface on touch, being in the state of inactivity, or dying) were considered as dead. The surviving larvae after the treatment were maintained separately. The process of selective inbreeding was repeated until 100\% survival at $0.01 \mathrm{mg} / \mathrm{L}$ was reported. Homozygous resistant strain was established after seventeen generations of selection and inbreeding.

About $50 \%$ of the larvae obtained from the isofemale of PRP strain were exposed to the above-mentioned dose to check for susceptibility. The untreated larvae from the line with highest percent of susceptibility were selected for inbreeding and the procedure was repeated for six generations to get the homozygous susceptible strain.

2.3. Genetic Crosses. Virgin adults of the susceptible and the resistant strains were reciprocally crossed (Susceptible Female $X$ Resistant Male and Resistant Female $X$ Susceptible Male) to produce the $F_{1} F$ hybrids. Part of $F_{1} F$ progeny from both reciprocal crosses were used for larval bioassay, and the remaining part of $\mathrm{F}_{1} \mathrm{~F}$ progeny from both reciprocal crosses were pooled and reared to adult stage for backcrossing to parental strains and intercrossing to produce the $\mathrm{F}_{2} \mathrm{~F}$ progeny. The resulting backcross $\left(\mathrm{F}_{1} \times \mathrm{S}\right)$ and the $\mathrm{F}_{2} \mathrm{~F}$ progeny were assessed in order to test the hypothesis of monogenic inheritance. The data was subjected to statistical analysis and mode of inheritance of insecticide resistance was carried out according to the procedure of Priester and Georghiou [16], and Mazzarri and Georghiou [17]. The null hypothesis of monogenic resistance was tested from mortality data of backcross progeny compared to theoretical expectations using the $\chi^{2}$ test. The degree of dominance $(D)$ was determined using the formula of Stones [18]. $D=\left(2 X_{2}-\right.$ $\left.X_{1}-X_{3}\right) / X_{1}-X_{3}$, where, $X_{1}, X_{2}$, and $X_{3}$ are the logarithms of the $\mathrm{LC}_{50}$ (concentration for $50 \%$ lethality) values for resistant, $\mathrm{F}_{1}$ hybrid, and susceptible strains, respectively. The value of $D$ varies from -1 to $1 ; D=1$ indicates complete dominance, $0<D<1$ incomplete dominance, $-1<D<0$ incomplete recessivity, and $D=-1$ complete recessivity [18].

2.4. Larval Bioassay Test. Twenty-five late third instar larvae were transferred into a glass bottle containing the test concentration $(249 \mathrm{~mL}$ of dechlorinated tap water $+1 \mathrm{~mL}$ stock concentration) each, with four replicates. Small amount of larval feed was added to avoid mortality due to starvation. Mortality was assessed after $24 \mathrm{hrs}$. Mortality data from bioassays were corrected by natural control mortality using Abbot's formula [19]. $\mathrm{LC}_{50}$ and $\mathrm{LC}_{90}$ were calculated by logdose probit analysis-LDP line [20].

\section{Results and Discussion}

The establishment of homozygous resistant (R) and susceptible (S) strains of An. stephensi for propoxur to a diagnostic dose of $0.01 \mathrm{mg} / \mathrm{L}$ is presented in Figure 1. Homozygous resistant and susceptible strains were synthesized by selective inbreeding for 17 and 6 generations, respectively. Exposure to diagnostic dose of propoxur exhibited gradual decrease in larval mortality with the progression of generations.

The data on various genetic crosses for susceptibility and resistance has been presented in Table 1 . The crosses between the susceptible male to susceptible female (cross 1) and resistant male to resistant female (cross 2 ) showed the purity of gamete for susceptibility and resistance, respectively. The $\mathrm{LC}_{50}$ of the resistant strain was 91.68 times greater than the $\mathrm{LC}_{50}$ of the susceptible strain. The dose response of parental strains was characterized by straight lines when bioassayed with propoxur, indicating that susceptible and resistant strains were homogeneous for susceptibility and resistance to this insecticide, respectively (Figure 2). When a female of the propoxur resistant strain was crossed with the susceptible strain (reciprocal cross), the $\mathrm{F}_{1}$ hybrids showed $51.85 \%$ and $48.15 \%$ of resistance and susceptibility, respectively (cross 3 ). Similar result of $53.93 \%$ of resistance and $46.07 \%$ of susceptibility was recorded in $\mathrm{F}_{1}$ hybrids of propoxur-resistant males crossed with susceptible females (cross 4). Both the abovementioned reciprocal crosses exhibit $1: 1$ ratio of susceptible and resistant response, which means, that the resulting $F_{1}$ hybrids from the reciprocal crosses were intermediate in their 


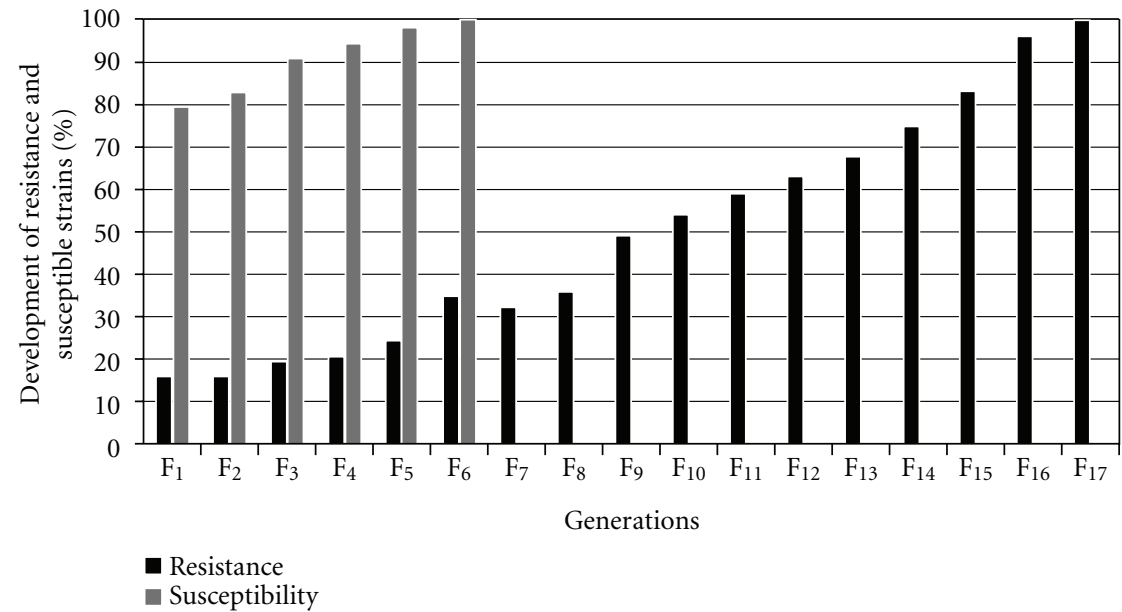

FIGURE 1: Development of propoxur-resistant and propoxur-susceptible strains in each generation.

TABLE 1: Inheritance pattern of propoxur resistance in Anopheles stephensi Liston.

\begin{tabular}{|c|c|c|c|c|c|c|c|c|c|c|c|c|}
\hline \multirow[t]{2}{*}{ S. No } & \multirow{2}{*}{$\begin{array}{l}\text { Genetic } \\
\text { crosses }\end{array}$} & \multirow[t]{2}{*}{$\begin{array}{l}\text { No. of o's } \\
\text { tested }\end{array}$} & \multirow[t]{2}{*}{$\begin{array}{l}\text { No. of larvae } \\
\text { tested }^{* *}\end{array}$} & \multicolumn{3}{|c|}{ Resistant } & \multirow[t]{2}{*}{$\begin{array}{l}\text { Resistant } \\
(\%)\end{array}$} & \multicolumn{3}{|c|}{ Susceptible } & \multirow[t]{2}{*}{ Susceptible (\%) } & \multirow[t]{2}{*}{$\chi^{2}$} \\
\hline & & & & $0^{\pi}$ & 우 & Total & & $0^{7}$ & q & Total & & \\
\hline \multicolumn{13}{|c|}{ Parental } \\
\hline 1 & $\mathrm{~S}^{7} \times \mathrm{S} p$ & 10 & 978 & - & - & - & - & 481 & 473 & 954 & 100 & - \\
\hline 2 & $\mathrm{Ro}^{7} \times \mathrm{R} Q$ & 10 & 835 & 378 & 432 & 810 & 100 & - & - & - & - & - \\
\hline \multicolumn{13}{|c|}{$\begin{array}{l}\mathrm{F}_{1} \\
\text { Generation }\end{array}$} \\
\hline 3 & $\mathrm{So}^{\top} \times \mathrm{R}_{+}$ & 10 & 648 & 142 & 194 & 336 & 51.85 & 118 & 194 & 312 & 48.15 & $0.44^{*}$ \\
\hline 4 & $\mathrm{Ro}^{7} \times \mathrm{S} \phi$ & 10 & 725 & 178 & 213 & 391 & 53.93 & 177 & 157 & 334 & 46.07 & $2.24^{*}$ \\
\hline \multicolumn{13}{|c|}{ Back Crosses } \\
\hline 5 & $\begin{array}{l}\mathrm{S}^{\top} \times \mathrm{F}_{1} \text { 早 } \\
{[\text { Cross 3] }}\end{array}$ & 10 & 834 & 240 & 195 & 435 & 52.16 & 189 & 210 & 399 & 47.84 & $0.78^{*}$ \\
\hline 6 & $\begin{array}{l}\mathrm{S} q \times \mathrm{F}_{1} \mathrm{O}^{7} \\
{[\text { Cross 3] }}\end{array}$ & 10 & 723 & 184 & 153 & 337 & 46.61 & 223 & 163 & 386 & 53.39 & $1.66^{*}$ \\
\hline 7 & $\begin{array}{l}\mathrm{So}^{\top} \times \mathrm{F}_{1} \text { ㅇ } \\
{[\text { Cross 4] }}\end{array}$ & 10 & 651 & 160 & 194 & 354 & 54.38 & 146 & 151 & 297 & 45.62 & $2.50^{*}$ \\
\hline 8 & $\begin{array}{l}\mathrm{S}_{q} \times \mathrm{F}_{1} \mathrm{O}^{7} \\
{[\text { Cross 4] }}\end{array}$ & 10 & 782 & 213 & 168 & 381 & 48.72 & 218 & 183 & 401 & 51.28 & $0.26^{*}$ \\
\hline \multicolumn{13}{|c|}{$\begin{array}{l}\mathrm{F}_{2} \\
\text { Generation }\end{array}$} \\
\hline 9 & $\mathrm{~F}_{1} \sigma^{\top} \times \mathrm{F}_{1}$ 우 & 10 & 912 & 282 & 212 & 494 & 54.17 & 187 & 231 & 418 & 45.83 & $3.17^{*}$ \\
\hline 10 & $\mathrm{~F}_{1} \mathrm{\sigma}^{\top} \times \mathrm{F}_{1}$ 우 & 10 & 898 & 223 & 241 & 464 & 51.67 & 229 & 205 & 434 & 48.33 & $0.50^{*}$ \\
\hline
\end{tabular}

larval response to propoxur, the inheritance being slightly on the recessive side. The results of bioassay for reciprocal cross progenies also showed no significant differences $(P<$ $.05)$ between $F_{1}$ generations (cross 3 and cross 4) (Table 1). Resistance was clearly observed in both sexes, this equality suggested that sex linkage of resistance did not occur and that the genetic basis of the propoxur resistance was autosomal. When the $\mathrm{F}_{1}$ hybrids were backcrossed with the susceptible parents, their progeny showed 52.16\%, 46.61\%, 54.38\%, and $48.72 \%$ resistance and $47.84 \%, 53.39 \%, 45.62 \%$, and
$51.28 \%$ susceptibility, respectively (cross 5,6,7,8). Progeny of backcrosses showed close fit to the $1: 1$ ratio of resistant and susceptible. The crosses 9 and 10 of $\mathrm{F}_{2}$ progeny showed $54.17 \%$ and $51.67 \%$ resistance and $45.83 \%$ and $48.33 \%$ susceptibility, respectively.

The position of $\mathrm{F}_{1} \mathrm{LD}-\mathrm{P}$ lines relative to the susceptible and resistant parental strains indicates the degree of dominance of the resistance. Since, the $\mathrm{F}_{1}$ LD-P line (Figure 2) is significantly more resistant than the intermediate but less resistant than the resistant parental strain, it indicates 


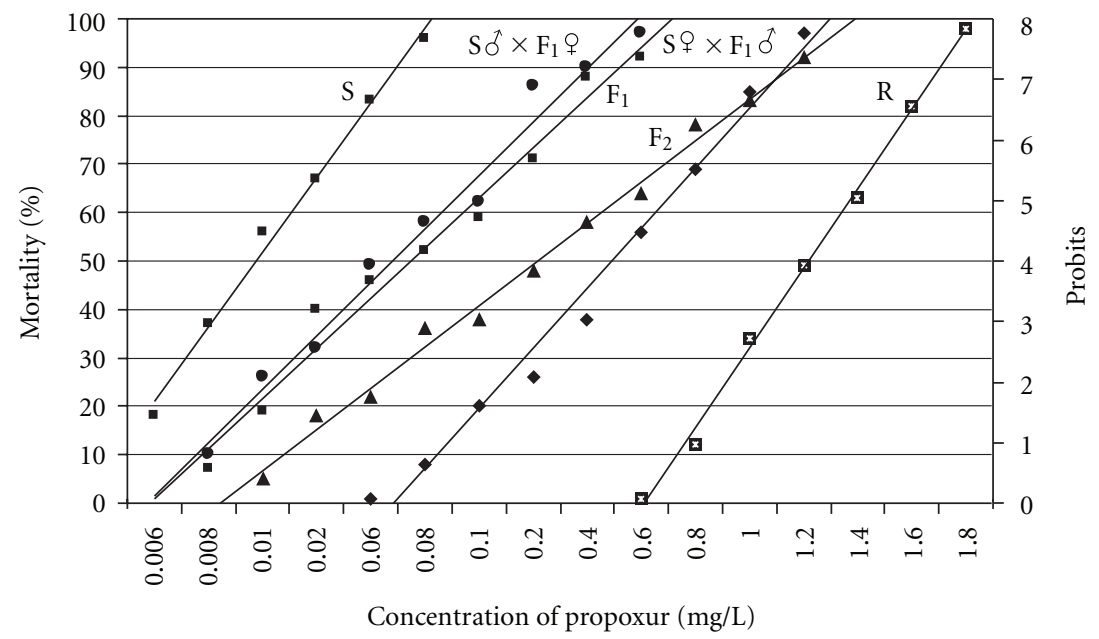

FIGURE 2: Dosage-mortality relationships of propoxur-resistant and propoxur-susceptible strains of An. stephensi.

incompletely dominant nature of the gene. Alternatively, the degree of dominance of the resistance response to propoxur (D) the based on the $\mathrm{LC}_{50}$ data was found to be 0.50 , indicating that the resistance was expressed as an incompletely dominant trait.

In the dose, response bioassay of the $\mathrm{F}_{2}$ or backcross offspring, monogenic control of resistance is indicated when a clear plateau of mortality is observed across a range of doses. When $F_{1}$ (RS) heterozygous individuals are backcrossed to the susceptible parent, monogenic resistance will result in a dose response curve with a clear plateau between LD-P lines of the SS and RS individuals at the 50\% mortality level, since $50 \%$ of the backcross offspring are RS heterozygotes that are unaffected over a range of insecticidal doses (Figure 2), indicating only a single gene was operational in conferring the resistance towards propoxur.

If the resistance is polygenic, recombination and independent assortment of $\mathrm{R}$ and $\mathrm{S}$ alleles of different loci will occur in $\mathrm{F}_{1}$ individuals. Backcrossing these individuals to susceptible individuals will result in offspring that include a number of genotypes that vary in their level of resistance. The shape of the LD-P line resulting from insecticide bioassay of these backcross individuals depends on a number of factors; in most cases a clear plateau will not be observed. If a number of unlinked genes contribute to resistance, the slope of the LD-P line should decrease compared to the lines for the susceptible and $\mathrm{F}_{1}$ individuals, and few backcross individuals will exhibit the level of resistance observed in the $F_{1}$ [21].

Present study thus reveals that a single gene is responsible for propoxur resistance in An. stephensi. Insecticide resistance in mosquitoes has been studied among many vectors and to various insecticides. Georghiou $[22,23]$ demonstrated the genetic basis of propoxur resistance in Culex pipiens quinquefasciatus as polygenic in nature. Mechanism of propoxur resistance induced by laboratory selection was also studied in Anopheles albimanus [24]. The genetic basis of several insecticides resistance has been studied in $A n$. stephensi in our laboratory. These include Malathion [25];
Fenthion and Methyl parathion [26]; Deltamethrin [27]; Fenitrothion [28]; Cypermethrin [29]; DDT [30]; Chlorpyrifos [31]; Temephos [10]; Neem and Bifenthrin [32]; Alphamethrin [33]. In Cx. Quinquefasciatus, inheritance mode for synthetic pyrethroid insecticide Deltamethrin and Cyfluthrin were found to be near dominant and autosomal [34], and in Ae. aegypti the inheritance mode was found to incompletely dominant and autosomal for two synthetic pyrethroid, namely, Alphamethrin and Malathion [35].

Understanding the resistance inheritance is also important for predicting the continuing and effective use of a chemical for a particular pest control [1]. The degree of dominance of resistance alleles plays a significant role in the expression and distribution of the resistant gene. Since resistance controlled by a single gene develops rapidly compares to that of resistance controlled by two or more genes [36], the data generated from the study could lead to a better understanding of the rate of resistance development by use of the information on the inheritance mode of the resistant gene involved.

\section{Conclusions}

The genetic basis of propoxur resistance in An. stephensi clearly showed that the gene $\mathrm{pr}$ is autosomal, monofactorial, and incompletely dominant. The propoxur-resistant gene $p r$ established in the present investigation has several applications in conducting basic and applied genetic research. It can be used as an excellent genetic marker in $A n$. stephensi. The insecticide-resistance gene can be used in synthesizing multiple markers, preparation of linkage maps, molecular mapping, and so forth. Such integrated strains could be used in studying the linkage relationship, to prepare the linkage map, chromosome linkage correlation, and in applied research including synthesis of refractory strains as well as genetic sexing strains (as a conditional lethal) for preferential elimination of females in the early developmental stages. 
Insecticide-resistant gene which is an autosomal (located in 2 or 3 chromosome) could be transferred to the male-determining chromosome via radiation-induced malelinked translocation. When the larvae from such line are exposed to the discriminating dose of insecticide all the females are killed, as the females do not have the resistant gene, and all the males will survive since they carry the resistant gene. Genetic sexing males thus obtained could be subjected for mating competitive ability with laboratorymaintained males and field-collected males in the presence of field-collected females in a large cage population. If the males (genetic sexing) compete higher than the normal males, pilot release experiments could be conducted in a selected area. Thus, the genetic sexing males could be used in the genetic control programme of any insect species through the sterile insect technique (SIT). Such genetic sexing strains have been synthesized in few species of mosquitoes including An. gambiae species A [37], An. albimanus [38], and An. Quadrimaculatus, species A [39]. In Cx. quinquefasciatus a sexing strain was synthesized for the preferential elimination of females during early larval stage by using a malathionresistance gene linked to male determining factor [40].

The expression of certain enzymes that are involved in two different types of resistance mechanisms, namely, metabolite resistance (esterases, phosphatases, dehydrogenases, etc.) and target site resistance (acetylcholine esterases) are very specific in their expression to each one of the insecticide resistant strains and their expression varied within the different life stages. Similarly, cytological studies carried out in polytene chromosomes from ovarian nurse cells of various insecticide resistant strains are characterized by the presence of specific heterozygous inversion (s) which are absent in other insecticide resistant strain (s) and in natural populations thus far studied $[41,42]$.

\section{Acknowledgment}

This paper has been supported by financial assistance from University Grants Commission (UGC), New Delhi, to Professor N. J. Shetty.

\section{References}

[1] J. C. Bouvier, R. Buès, T. Boivin, L. Boudinhon, D. Beslay, and B. Sauphanor, "Deltamethrin resistance in the codling moth (Lepidoptera: Tortricidae): inheritance and number of genes involved," Heredity, vol. 87, no. 4, pp. 456-462, 2001.

[2] R. T. Roush and J. C. Daly, "The role of population genetics in resistance research and management," in Pesticide Resistance in Arthropods, R. T. Roush and B. E. Tabashnik, Eds., pp. 97-152, Chapman and Hall, London, UK, 1990.

[3] W. G. Brogdon and J. C. McAllister, "Insecticide resistance and vector control," Emerging Infectious Diseases, vol. 4, no. 4, pp. 605-613, 1998.

[4] WHO/SEARO, "Insecticide resistance in mosquito vectors of disease," Report of a regional working Group Meeting Salatiga (Indonesia), SEA/VBC/59, August 1997.

[5] F. Catteruccia, T. Holan, T. G. Loukeris et al., "Stable germline transformation of the malaria mosquito Anopheles stephensi," Nature, vol. 405, no. 6789, pp. 959-962, 2000.
[6] J. Hemingway and H. Ranson, "Insecticide resistance in insect vectors of human disease," Annual Review of Entomology, vol. 45, pp. 371-391, 2000.

[7] N. J. Shetty, "The genetic control of Anopheles stephensi-a malaria mosquito," in Trends in Malaria and Vaccine Research: The Current Indian Scenario, D. Raghunath and R. Nayak, Eds., pp. 44-79, Tata Mcgraw-Hill, New Delhi, India, 2002.

[8] N. J. Shetty, "Genetic control of mosquito vectors of diseases," Journal of Parasitic Diseases, vol. 21, pp. 113-121, 1997.

[9] A. D. Madhyastha and N. J. Shetty, "Ruby-eye, a new autosomal mutant in the malaria mosquito, Anopheles stephensi Liston," Indian Journal of Medical Research, vol. 115, pp. 194200, 2002.

[10] D. Sanil and N. J. Shetty, "Genetic study of temephos resistance $(t r)$, an organophosphate insecticide in the malaria mosquito, Anopheles stephensi Liston," The Journal of Cytology \& Genetics, vol. 11, pp. 15-22, 2009.

[11] T. P. N. Hariprasad and N. J. Shetty, "Sienna an autosomal eye colour mutant linked with grayish brown, dark and green thorax in Anopheles stephensi Liston," The Journal of Cytology \& Genetics, vol. 10, no. 2, pp. 29-37, 2009.

[12] World Health Organization, "Monitoring of insecticide resistance in malaria vector," in WHO Roll Back Malaria Publications, p. 8, Cairo, Egypt.

[13] N. J. Shetty, "Chromosomal translocation and semisterility in the malaria vector Anopheles fluviatilis James," Indian Journal of Malariology, vol. 20, pp. 45-48, 1983.

[14] World Health Organization, "Instructions for determining susceptibility or resistance of mosquito larvae of insecticide," WHO/ VBC-81 pp 807,. 1981.

[15] World Health Organization, "Guidelines for laboratory and field testing of mosquito larvicides," WHOPES, 2005.

[16] T. M. Priester and G. P. Georghiou, "Penetration of permethrin and knockdown in larvae of pyrethroid-resistant and susceptible strains of the Southern House mosquito," Journal of Economic Entomology, vol. 73, pp. 165-167, 1980.

[17] M. B. Mazzarri and G. P. Georghiou, "Characterization of resistance to organophosphate, carbamate, and pyrethroid insecticides in field populations of Aedes aegypti from Venezuela," Journal of the American Mosquito Control Association, vol. 11, no. 3, pp. 315-322, 1995.

[18] B. F. Stone, "A formula for determining degree of dominance in cases of monofactorial inheritance of resistance to chemicals," Bulletin of the World Health Organization, vol. 38, no. 2, pp. 325-326, 1968.

[19] W. S. Abbott, "A method for computing the effectiveness of an insecticide," Journal of Economic Entomology, vol. 18, pp. 265267, 1925.

[20] D. J. Finney, Probit Analysis, Cambridge University Press, Cambridge, UK, 3rd edition, 1971.

[21] J. A. Ferrari, "Insecticide resistance," in The Biology of Disease Vectors, B. J. Beaty and W. C. Marquardt, Eds., pp. 512-516, University press of Colorado, 1996.

[22] G. P. Georghiou, "Development and characterization of resistance to o-lsopropoxyphenyl methyl-carbamate in the mosquito Culex pipiens quinquefasciatus say," Nature, vol. 207, no. 4999, pp. 883-884, 1965.

[23] G. P. Georghiou, "Genetic studies on insecticide resistance," Advances in Pest Control Research, vol. 6, pp. 171-230, 1965.

[24] V. Ariaratnam and G. P. Georghiou, "Carbamate resistance in Anopheles albimanus. Cross resistance spectrum and stability of resistance," Bulletin of the World Health Organization, vol. 51, no. 6, pp. 655-659, 1975. 
[25] D. E. G. Rao and N. J. Shetty, "Genetic study of malathion resistance in Anopheles stephensi," The Journal of Cytology \& Genetics, vol. 29, pp. 215-219, 1994.

[26] D. E. G. Rao and N. J. Shetty, "Esterase isozyme of organoposphate resistant strains in An. stephensi, Liston," in Proceedings of the 3rd National Seminar on Malaria and other Tropical Diseases, p. 34, 1997, (abstract).

[27] B. H. Rajashree and N. J. Shetty, "Genetic study of deltamethrin resistance in the malaria mosquito Anopheles stephensi Liston," Journal of Parasitic Diseases, vol. 22, pp. 140$143,1998$.

[28] C. Ghosh and N. J. Shetty, "Mode of inheritance of fenitrothion resistance in Anopheles stephensi Liston," The Journal of Cytology \& Genetics, vol. 34, pp. 141-146, 1999.

[29] B. L. Priyalakshmi and N. J. Shetty, "Genetic study of cypermethrin resistance in the malaria mosquito Anopheles stephensi Liston," Journal of Parasitic Diseases, vol. 22, pp. 140$143,2000$.

[30] B. N. Chandrakala and N. J. Shetty, "Genetic studies of DDT resistance in the malaria mosquito Anopheles stephensi Liston," The Journal of Cytology \& Genetics, vol. 5, pp. 185-190, 2004.

[31] B. N. Chandrakala and N. J. Shetty, "Genetic studies of chloropyrifos resistance in the malaria mosquito Anopheles stephensi Liston," The Journal of Cytology \& Genetics, vol. 7, pp. 155-160, 2006.

[32] Z. Thant and N. J. Shetty, "Genetic studies of neem (botanical insecticide) and bifenthrin (synthetic pyrethroid) resistance in Anopheles stephensi Liston," unpublished.

[33] T. P. N. Hariprasad and N. J. Shetty, "Genetic studies of alphamethrin (synthetic pyrethroid) resistance in Anopheles stephensi Liston," unpublished.

[34] A. Shashikanth and N. J. Shetty, "Genetic studies of deltamethrin and cyfluthrin (synthetic pyrethroid) resistance in Culex quinquefasciatus," unpublished.

[35] M. Z. Myin, T. Zin, and N. J. Shetty, "Genetic study of alphamethrin resistance in Aedes aegypti (Linnaeus 1762), a dengue mosquito," Journal of the Myanmar Academy of Arts and Science, vol. 3, no. 4, pp. 111-119, 2009.

[36] B. E. Tabashnik, "Computer stimulation as a tool for pesticide resistance management," in Pesticide Resistance: Strategies and Tactics for Management, pp. 195-203, National Academy Press, Washington, DC, USA, 1986.

[37] C. F. Curtis, J. Akiyama, and G. Davidson, "A genetic sexing system in Anopheles gambiae species A," Mosquito News, vol. 36, pp. 492-498, 1976.

[38] J. A. Seawright, P. E. Kaiser, D. A. Dame, and C. S. Lofgren, "Genetic method for the preferential elimination of females of Anopheles albimanus," Science, vol. 200, no. 4347, pp. 13031304, 1978.

[39] S. S. Kim, J. A. Seawright, and P. E. Kaiser, "A genetic sexing strain of Anopheles quadrimaculatus, species A," Journal of the American Mosquito Control Association, vol. 3, no. 1, pp. 5053, 1987.

[40] N. J. Shetty, "Genetic sexing system for the preferential elimination of females in Culex quinquefasciatus," Journal of the American Mosquito Control Association, vol. 3, no. 1, pp. 84-86, 1987.

[41] C. Ghosh and N. J. Shetty, "Tests for association of fenitrothion resistance with inversion polymorphism in the malaria vector, Anopheles stephensi," The Nucleus, vol. 47, no. 3, pp. 164-168, 2004.

[42] N. J. Shetty et al., "Genetical, biochemical and cytological studies of insecticide resistance strains in Anopheles stephensi Liston, a malaria mosquito," unpublished. 


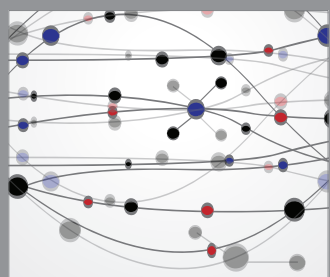

The Scientific World Journal
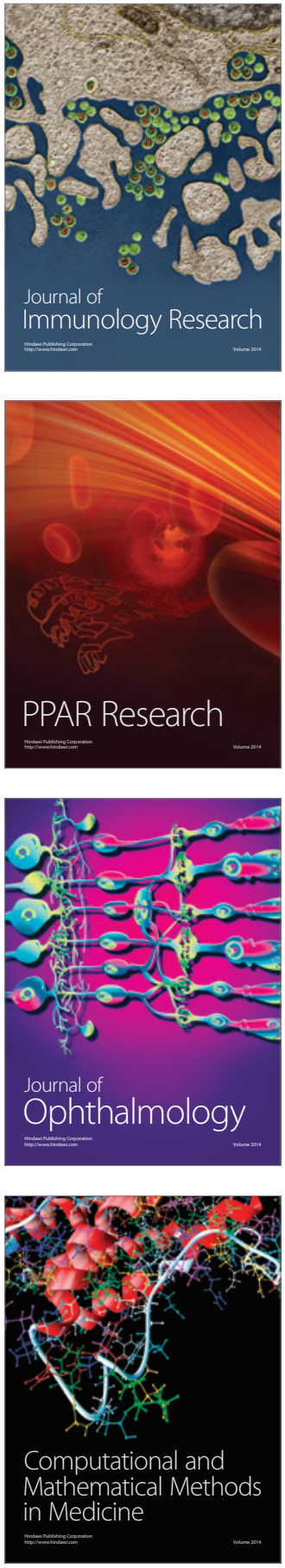

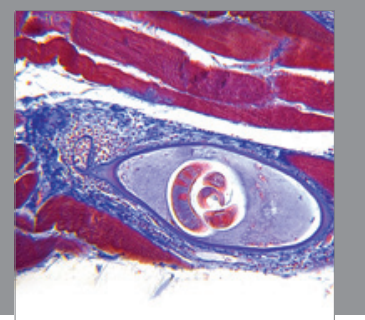

Gastroenterology

Research and Practice
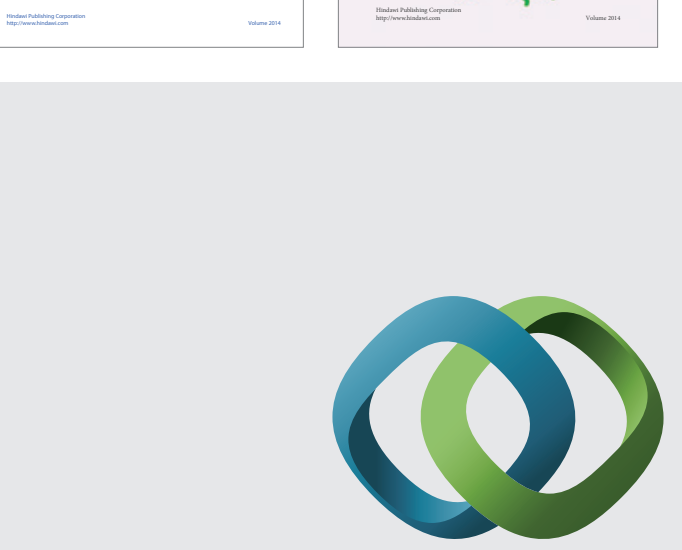

\section{Hindawi}

Submit your manuscripts at

http://www.hindawi.com
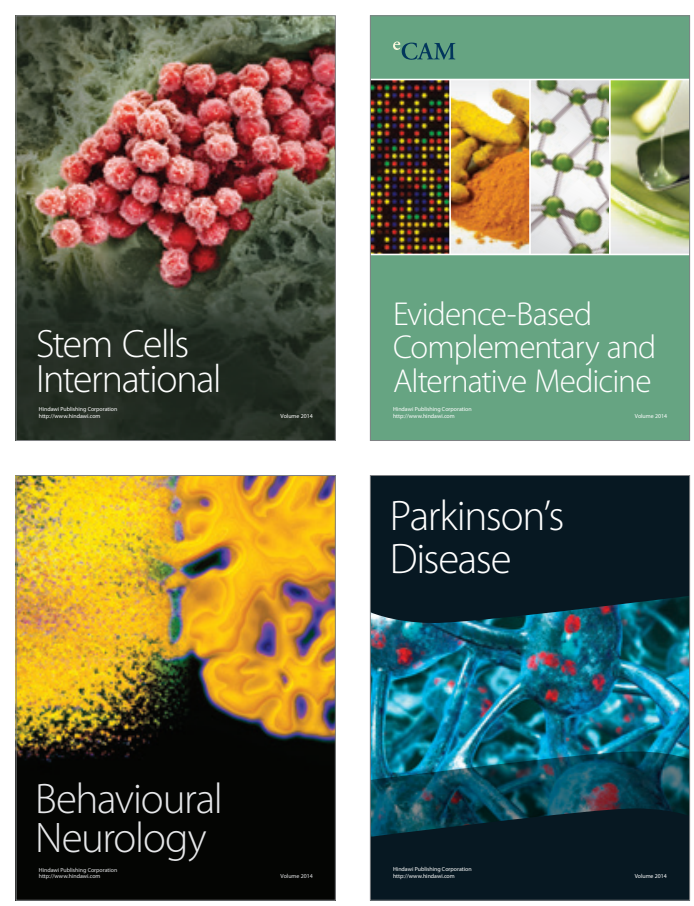

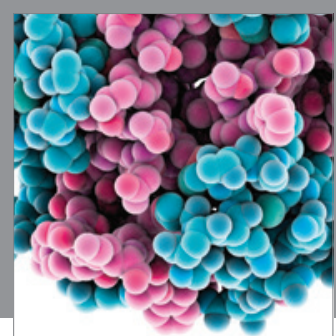

Journal of
Diabetes Research

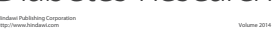

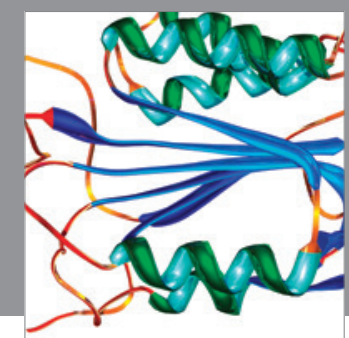

Disease Markers
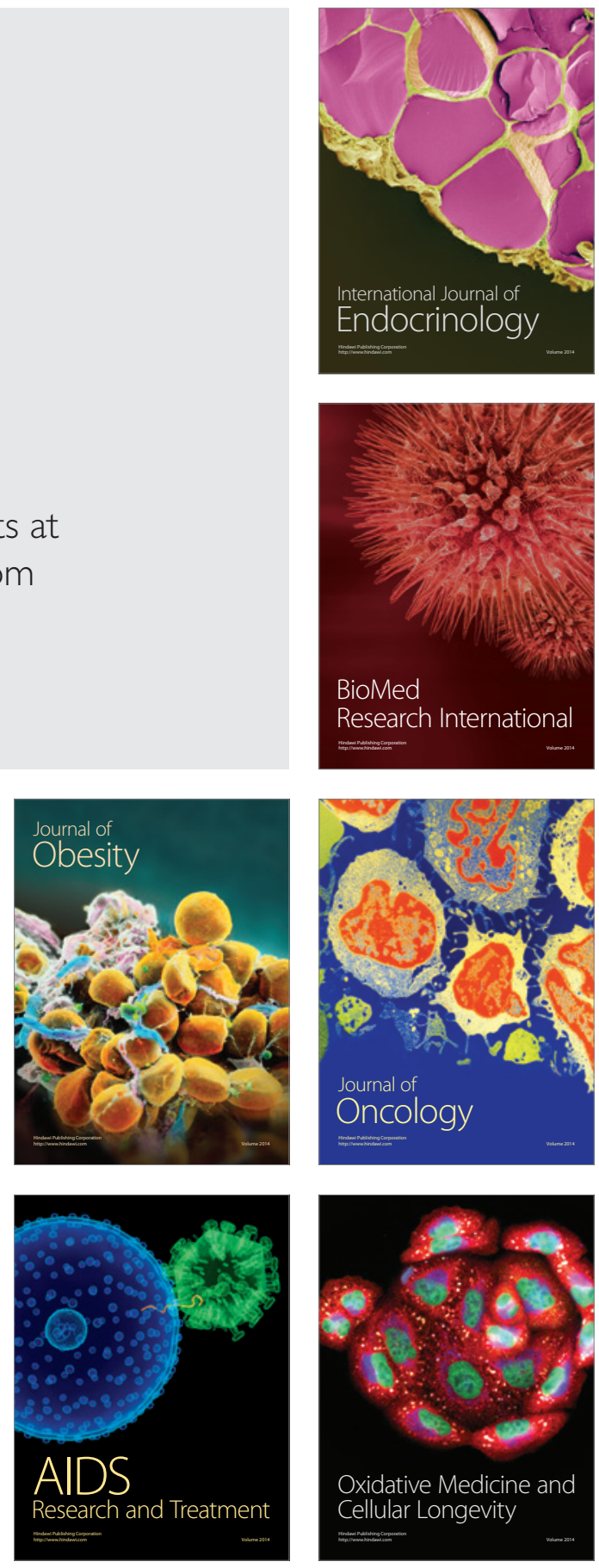